\title{
Oxidation of oximes with hypervalent iodine reagents: opportunities, development, and applications
}

\author{
Charles Dylan Turner and Marco A. Ciufolini \\ Department of Chemistry, University of British Columbia, 2036 Main Mall \\ Vancouver, BC V6T 1Z1, Canada \\ E-mail: ciufi@chem.ubc.ca
}

\begin{abstract}
The paper reviews the oxidation of oximes to nitrile oxides with hypervalent iodine reagents, especially $\mathrm{PhI}(\mathrm{OAc})_{2}$, and the synthetic uses of such a transformation. Side reactions attending the process are also discussed.
\end{abstract}

Keywords: Hypervalent iodine reagents, dipolar cycloaddition, nitrile oxides, oximes, heterocycles

\section{Contents}

1. Introduction

2. Desymmetrization of Dienones obtained through Oxidative Amidation Reactions

3. Tandem Oxidative Amidation /Intramolecular Nitrile Oxide Cycloaddition Reactions

4. Other Processes involving the Reactions of Oximes with Hypervalent Iodine Reagents

5. Conclusions

6. Acknowledgements

7. References

\section{Introduction}

Hypervalent organoiodine compounds ${ }^{1}$ have emerged as uniquely capable oxidants in a number of noteworthy transformations, some of which are all but unachievable by the use of alternative reagents. For instance, $\mathrm{PhI}\left(\mathrm{OCOCH}_{3}\right)_{2}$ (DIB), or occasionally $\mathrm{PhI}\left(\mathrm{OCOCF}_{3}\right)_{2}$ (PIFA), serve as exquisite promoters of the oxidative amidation of phenols, ${ }^{2}$ a special case of oxidative dearomatization of phenols ${ }^{3}$ exemplified in Scheme $1 .{ }^{4}$ Low toxicity and environmentally benign nature amplify the practical value of such oxidants. 


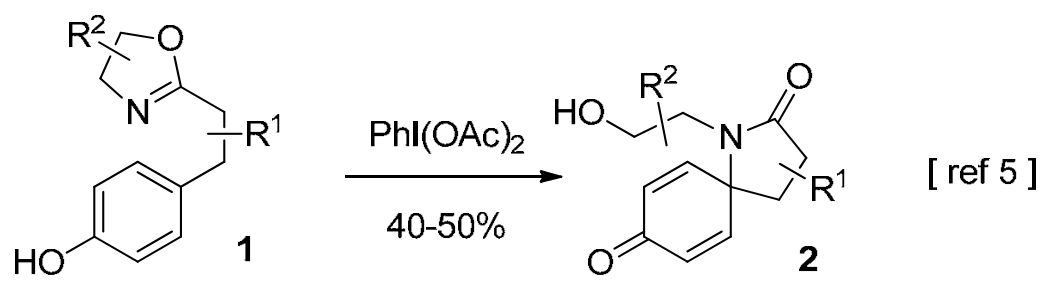<smiles>[R]CCN[SH]([R2])(=O)NCc1ccc(O)cc1</smiles><smiles>[R]C(=O)NC1([R])C=CC(=O)C=C1</smiles>

Scheme 1. The oxidative amidation of phenols.

Three modes of oxidative phenolic amidation are known at this time: the oxidative cyclization of phenolic oxazolines $(\mathbf{1} \rightarrow \mathbf{2})^{5}$ or sulfonamides $(\mathbf{3} \rightarrow \mathbf{4}){ }^{6}$, both of which are intramolecular reactions, and the bimolecular Ritter-like amidation in the presence of nitriles $(5 \rightarrow 6){ }^{7}$ Investigations centering on the application of these transformations to the synthesis of certain natural products revealed the desirability of engaging the emerging dienones in a nitrile oxide cycloaddition ("INOC") reaction, ${ }^{8}$ ideally, within the context of a tandem oxidative amidation / INOC sequence. A number of considerations induced us to focus on the oxidation of oximes with hypervalent iodine reagents as a means to generate nitrile oxides in a manner consonant with the foregoing objective. Research in that sense ultimately produced excellent solutions. In addition, it stimulated significant activity in other domains of chemical science, including bio-organic, main-group, and materials chemistry. The present contribution highlights key developments in these areas, and it covers literature published through June 2011.

\section{Desymmetrization of Dienones obtained through Oxidative Amidation Reactions}

The incentive for revisiting the oxidation of oximes with hypervalent iodine reagents emanated from a desire to create a tetrasubstituted, N-bearing stereogenic carbon of a specific configuration in connection with a particular synthetic objective (vide infra). The stereoselective assembly of such carbon centers is generally difficult, but the desymmetrization of a "locally symmetrical" dienones 
ensuing from an oxidative amidation reaction provides an effective and straightforward solution. As apparent from Scheme 2, this entails the selective addition of an.

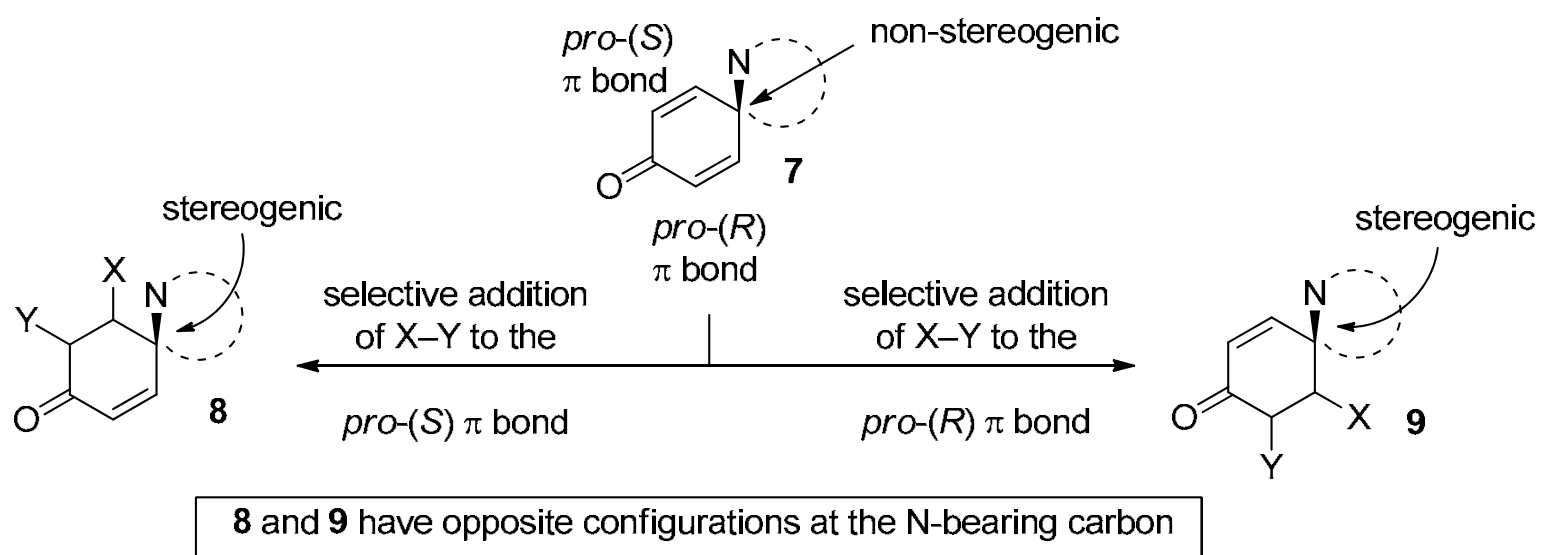

Scheme 2. Desymmetrization of "locally symmetrical" dienones 7

Appropriate agent, $\mathrm{X}-\mathrm{Y}$, either to the pro- $(R)$ or the pro- $(S)$ double bond. The various methods that were devised to that end were inspired by the observation that conformational effects can elicit selective reactivity at a particular diastereotopic $\pi$ bond of the dienone. For instance, spirolactam 10 undergoes highly stereoselective cyclization to 11 upon standing (Scheme 3). ${ }^{5 b}$ Evidently, welldocumented conformational effects direct the $\mathrm{OH}$ group selectively to the pro- $(R)$-double bond of 10. ${ }^{9}$ This translates into a highly selective formation of the $(R)$-configuration of the spiro center in 11.

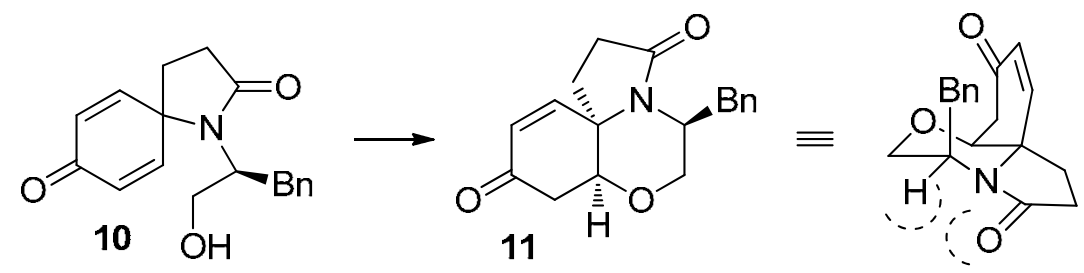

Scheme 3. Stereoselective Michael cyclization of $\mathbf{1 0 .}$

On the basis of the foregoing observation, we charted a synthesis of (-)-cylindricine $\mathrm{C}$ and putative $(+)$-lepadiformine ${ }^{6 \mathrm{~b}-\mathrm{c}}$ that relied on dienone desymmetrization via a stereocontrolled Michael cyclization of the anion of mesylamide 12 (Scheme 4). When compound 12, P = TIPS, was deprotonated with KHMDS, products $\mathbf{1 3}$ and $\mathbf{1 4}$ were formed in a 7:1 ratio. The selectivity in favor of 13 increased to 14:1 when unprotected $12(\mathrm{P}=\mathrm{H})$ was treated with 2 equivalents of LHMDS. For TIPS-protected substrates, the stereochemical result may be explained by invoking preferential cyclization from conformer anti-15, in which the sulfonyl unit experiences a reduced degree of steric compression against the short side chain relative to conformer syn-15. In the unprotected 
series, cyclization is likely to proceed from a Li-chelate such as $\mathbf{1 6}$, wherein the anion of the sulfonamide is directed to add to the pro- $(R)$ double bond of the dienone.

The reactions of Schemes 3-4 embody "nucleophilic" modes of dienone desymmetrization. A "pericyclic" variant of this process was recently demonstrated through intramolecular Diels- Alder (IMDA) chemistry. As detailed in Scheme 5, oxidative cyclization of sulfonamide 17 in trifluoroacetic acid (TFA) and in situ heating of the resultant 18 afforded an 8:1 mixture of products 20 (major, desired) and 21. Clearly, the IMDA step occurs preferentially from the less sterically congested conformer anti-18, leading to the desired 20. Interestingly, the primary adduct 19 underwent in situ acid-catalyzed epimerization of the stereocenter adjacent to the carbonyl group to produce the thermodynamically more favorable trans fusion between the two six-membered rings. Four stereogenic carbons, including a spiro center, are thus created stereoselectively in a single operation. Substance $\mathbf{2 0}$ is structurally related to the core of the unusual alkaloid, himandrine, albeit it possesses the antipodal configuration. ${ }^{10}$
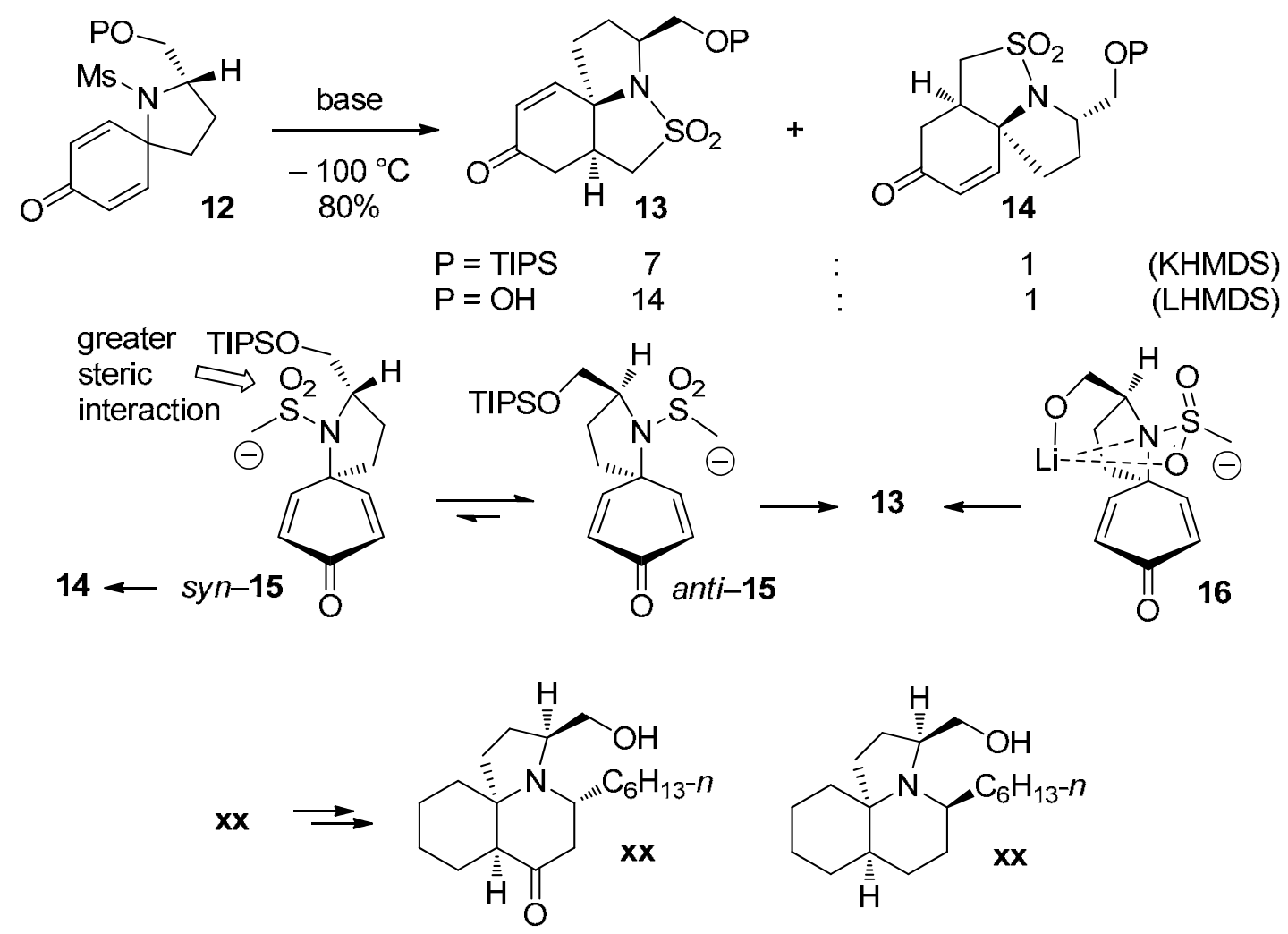

Scheme 4. Stereoselective Michael cyclization of sulfonamide 12. 


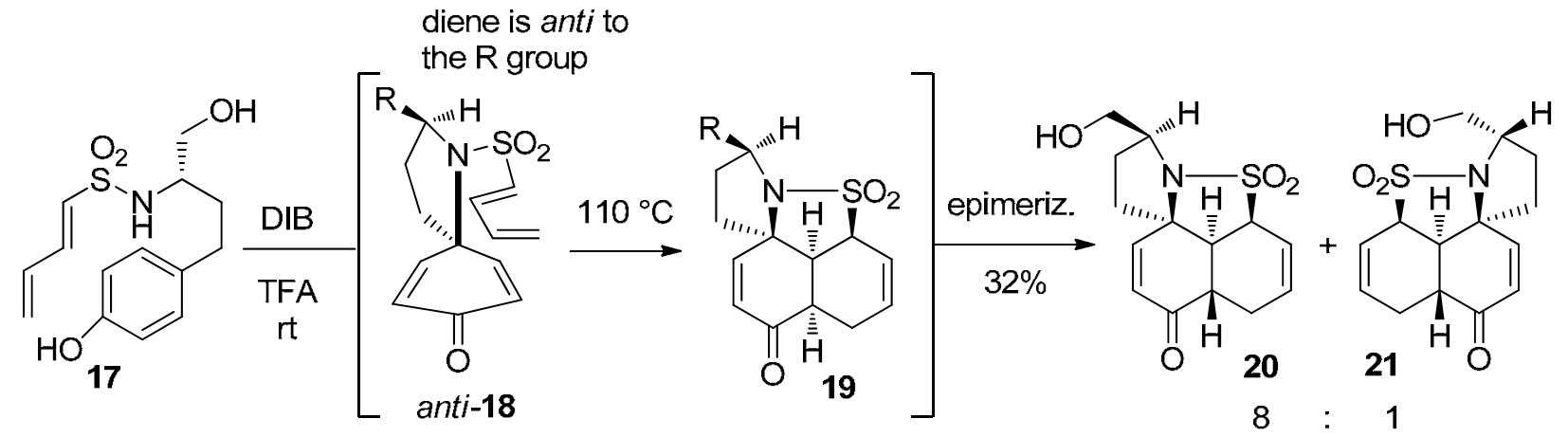

Scheme 5. Stereoselective IMDA cyclization of sulfonamide 18.

\section{Tandem Oxidative Amidation /Intramolecular Nitrile Oxide Cycloaddition Reactions}

The desirability of dienone desymmetrization via 1,3-dipolar cycloaddition reactions of nitrile oxides materialized in connection with an ongoing synthesis of tetrodotoxin, 22 ("TTX", Scheme 6). ${ }^{11}$ Simplification of the molecule leads to precursor $\mathbf{2 3}$, which could be obtained by bisdihydroxylation of diene 24, wherein the groups in parentheses represent expressed or latent forms of the $\mathrm{CHO}$ and $\mathrm{COOH}$ functionalities. In turn, $\mathbf{2 4}$ may derive from $\mathbf{2 5}$ by fragmentation of the isooxazoline ring and Wittig reaction. The assembly of $\mathbf{2 5}$ may proceed via oxidative amidation of phenol 28 and intramolecular nitrile oxide cycloaddition ${ }^{12}$ of $\mathbf{2 6}$.

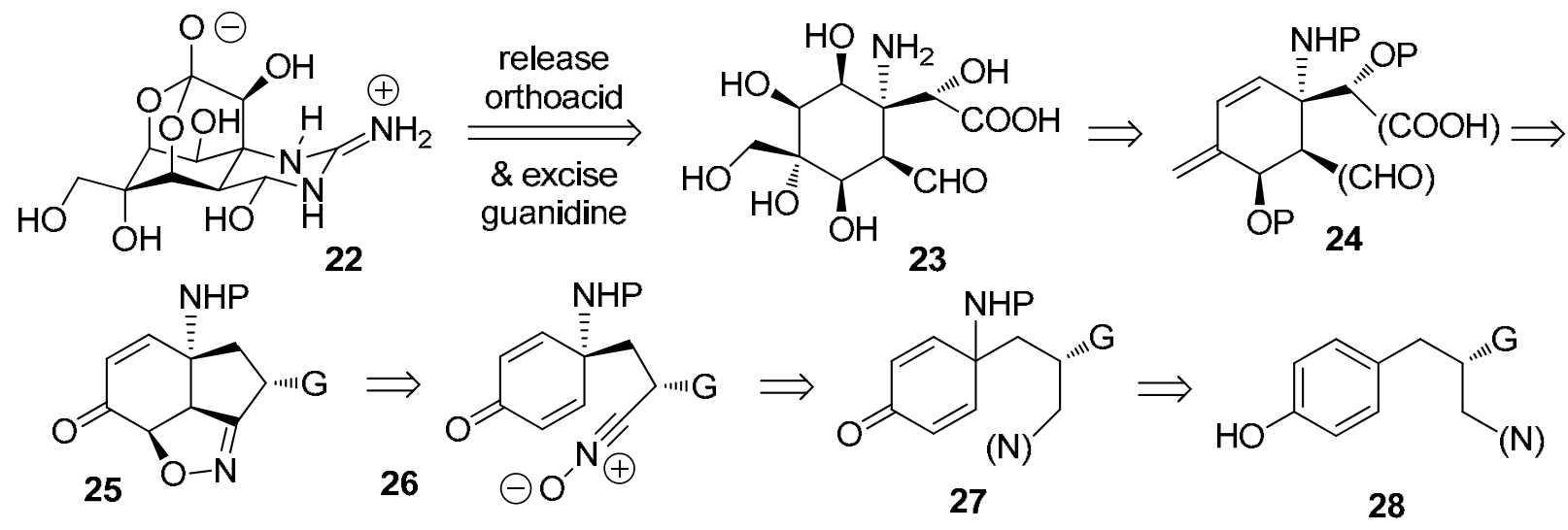

Scheme 6. Approach to tetrodotoxin, 22.

Substituent (N) in 27-28 stands for a nitrogenous functionality suitable for the generation of a nitrile oxide, while $\mathrm{G}$ is a group that must fulfill a number of requirements. First, it must be sufficiently bulky to direct the nitrile oxide segment of $\mathbf{2 6}$ to the pro-(S) double bond, resulting in selective formation of the desired $\mathbf{2 5}$. Indeed, a sterically demanding $\mathrm{G}$ would preferentially reside outside the developing bowl-shaped tricyclic product, favoring cyclization through transition state 
29, leading to the requisite 25 (Scheme 7). By contrast, transition state 30, which leads to the undesired regioisomer of the product, would force $\mathrm{G}$ within the developing bowl, creating severe congestion. Second, G must enable oxazoline fragmentation as well as the elaboration of the $\alpha$ hydroxyacid functionality found in intermediate $\mathbf{2 3}$. Finally, it should be such that the starting $\mathbf{2 8}$ is readily available in enantiopure form. Interestingly, if group $(\mathrm{N})$ were amenable to conversion into a nitrile oxide under the same conditions employed for the oxidative amidation step (reaction with hypervalent iodine agents), then 28 could be advanced to 25 by a tandem oxidative amidation / INOC reaction. The only proviso is that the rate of oxidation of $(\mathrm{N})$ to a nitrile oxide should be slower than that of the oxidative amidation, so that the dienone may already be in place by the time that the nitrile oxide begins to form.

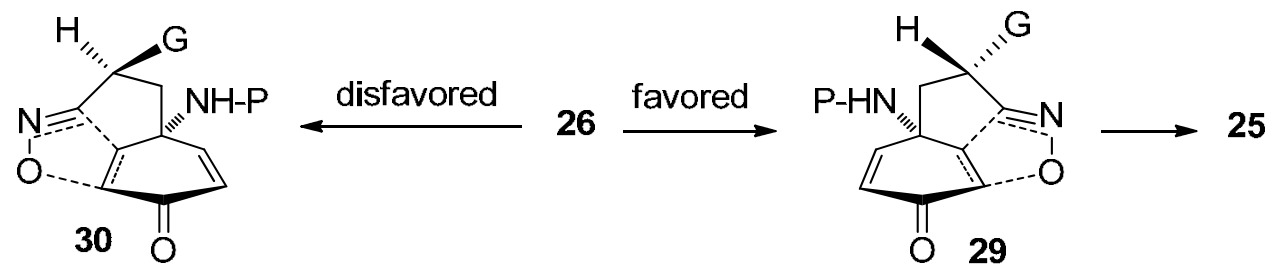

Scheme 7. Stereoselective INOC cyclization directed by substituent G.

A logical choice for $(\mathrm{N})$ appeared to be an aldoxime. Indeed, the literature records examples of oxidation of aldoximes to nitrile oxides with hypervalent iodine reagents, including $\mathrm{PhICl}_{2}{ }^{13}$ $\mathrm{PhIO},{ }^{14}$ and, subsequent to the publication of the results we are about to describe, with $\mathrm{PhI}(\mathrm{OTs}) \mathrm{OH}$ (Koser's reagent). ${ }^{15}$ Especially relevant to our objectives was the pioneering work of Das, who had previously described the oxidation of aldoximes to nitrile oxides with DIB: the reagent of choice for the oxidative amidation of phenols. ${ }^{16}$ However, all such reactions employ conditions that are unsuitable for the conduct of a tandem oxidative amidation/INOC sequence. In particular, it was unclear whether the chemistry described in these reports would perform adequately in the solvents normally employed for oxidative amidation reactions, i.e. trifluoroethanol (TFE) or hexafluoroisopropanol (HFIP, oxidative cyclization of oxazolines and some sulfonamides), or neat TFA (most sulfonamides), or acetonitrile containing a catalytic amount of TFA (bimolecular oxidative amidation).

We note that nitrile oxide formation occurs in a range of solvents, even nonpolar ones like toluene. A relevant example drawn from the work of Yang is shown in Scheme $8 .{ }^{17}$ Our exploration of alternative media was dictated uniquely by a projected need to induce INOC reactions in tandem with oxidative amidation events and related transformations. It should also be emphasized that the feasibility of a tandem oxidative amidation / INOC reaction in protic solvents was not at all certain at the onset of the studies detailed below, because the action of DIB upon oximes may induce a number of side reactions. ${ }^{18}$ 

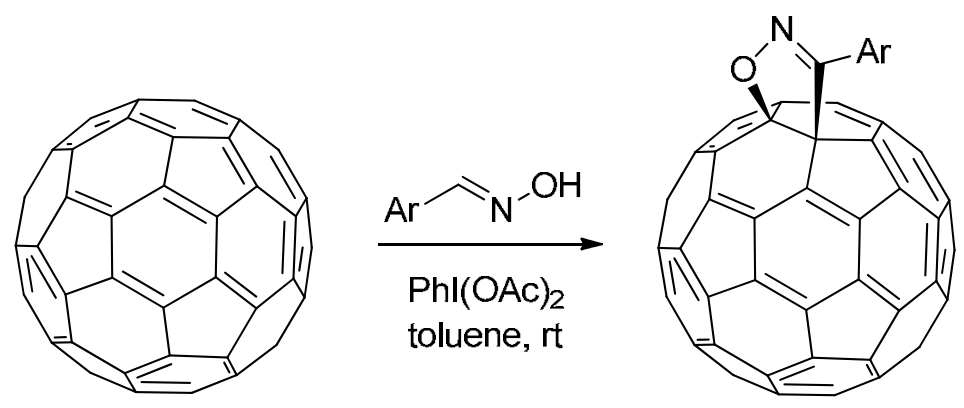

$20-50 \%$

Scheme 8. Oxidation of aromatic oximes to nitrile oxides with DIB in toluene.

Initial experiments ascertained that DIB smoothly oxidizes aldoximes to nitrile oxides in solvents compatible with oxidative amidation chemistry. ${ }^{19}$ This enabled the conduct of the tandem processes adumbrated in Scheme 9. Thus, exposure of $\mathbf{3 1}$ to DIB (2.2 equiv) in $\mathrm{MeCN}$ in the presence of TFA afforded 32 ( $71 \%$ yield after chromatography), the structure of which was ascertained by X-ray diffractometry. More importantly, $( \pm)$-tyrosine-derived 33, wherein the bulky $\mathrm{N}$-benzyl tosylamide substituent functions now as group $\mathrm{G}$ in $\mathbf{2 8}$, was converted into ( \pm )-34, single diastereomer, as the sole identifiable product in $44 \%$ chromatographed yield. A NOESY-2D experiment unveiled strong dipolar coupling between the indicated protons, confirming the relative configuration shown. The genesis of this particular diastereomer of the product is entirely consistent with the hypothesis formulated earlier in Scheme 7.
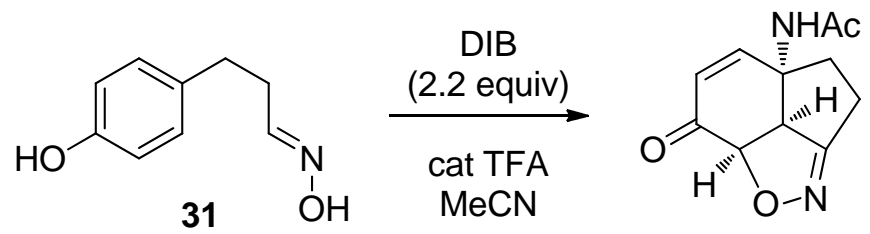

$3271 \%$ (X-rays)<smiles>O/N=C/C(Cc1ccc(O)cc1)N([13S])Cc1ccccc1</smiles>

$( \pm)-33$

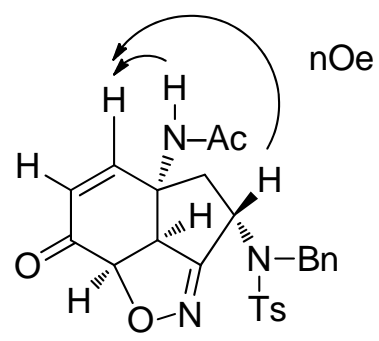

$( \pm)-34 \quad 44 \%$

Scheme 9. Tandem bimolecular oxidative amidation / INOC reaction.

We stress that a catalytic amount of TFA acts as an effective Bronsted acid promoter of oxime oxidation. In its absence, nitrile oxide formation may proceed inefficiently and side reactions are apt to occur, especially when operating in $\mathrm{MeCN}$ as the solvent. In that respect, Patel and collaborators 
have shown that the reaction of aldoximes with Koser's reagent or DIB in $\mathrm{MeCN}$ at $60{ }^{\circ} \mathrm{C}$, without added TFA, can lead to hydroxamic acids or the corresponding O-acetyl derivatives (Scheme 10). ${ }^{20}$ While the authors correctly suggest that $\mathbf{3 6}$ and $\mathbf{3 7}$ could originate from a nitrile oxide intermediate, alternative mechanisms for the formation of the observed products may also be envisaged, and cannot be excluded at this time.

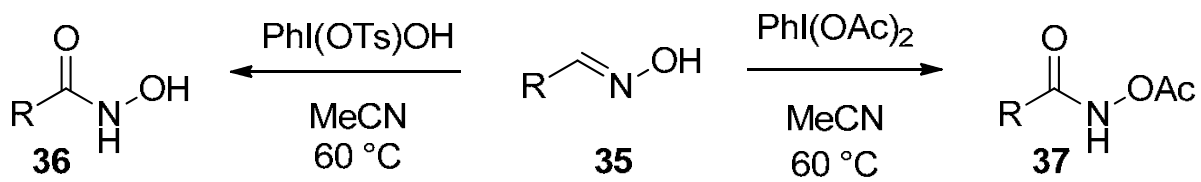

Scheme 10. Oxidation of aldoximes to hydroxamic acids in $\mathrm{MeCN}$ without added TFA.

\section{Other Processes Involving the Reactions of Oximes with Hypervalent Iodine Reagents}

In the course of our investigations, we observed that methanol containing a catalytic amount of TFA is one of the best solvents for DIB-mediated nitrile oxide generation from oximes. It should be noted that $\mathrm{MeOH}$ is unsuitable for the conduct of oxidative amidation reactions, in that being nucleophilic, it will rapidly intercept electrophilic intermediates arising through DIB activation of phenols. For example, the reaction of $\mathbf{3 1}$ with DIB in $\mathrm{MeOH} / \mathrm{TFA}$ produced compound $\mathbf{3 8}$ in $51 \%$ yield via a tandem oxidative methoxylation/INOC sequence (Scheme 11). ${ }^{19}$
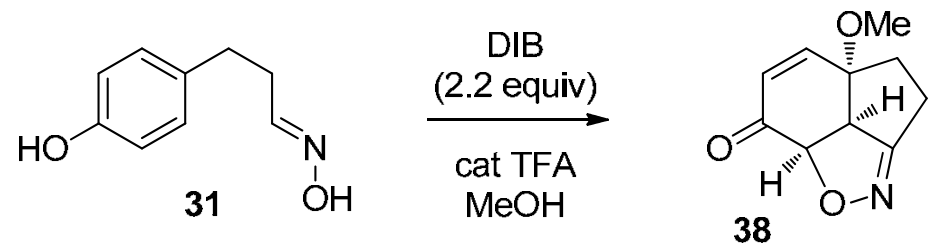

$51 \%$ (after

chromatography)

Scheme 11. Tandem bimolecular oxidative methoxylation / INOC reaction.

Non-solvolytic alkoxylation of the phenol prior to INOC reaction becomes possible by operating in non-nucleophilic protonic solvents such as TFE and HFIP. A noteworthy example of this chemistry has been described by Sorensen (Scheme 12). ${ }^{21}$ Specifically, attack of compound 39 with DIB in TFE resulted in cyclization to presumed intermediate 40, which converged to the ultimate $\mathbf{4 2}$ after in situ oxidation of the oxime to a nitrile oxide and INOC cyclization. Substance $\mathbf{4 2}$ is structurally related to the interesting natural product, cortistatin. 


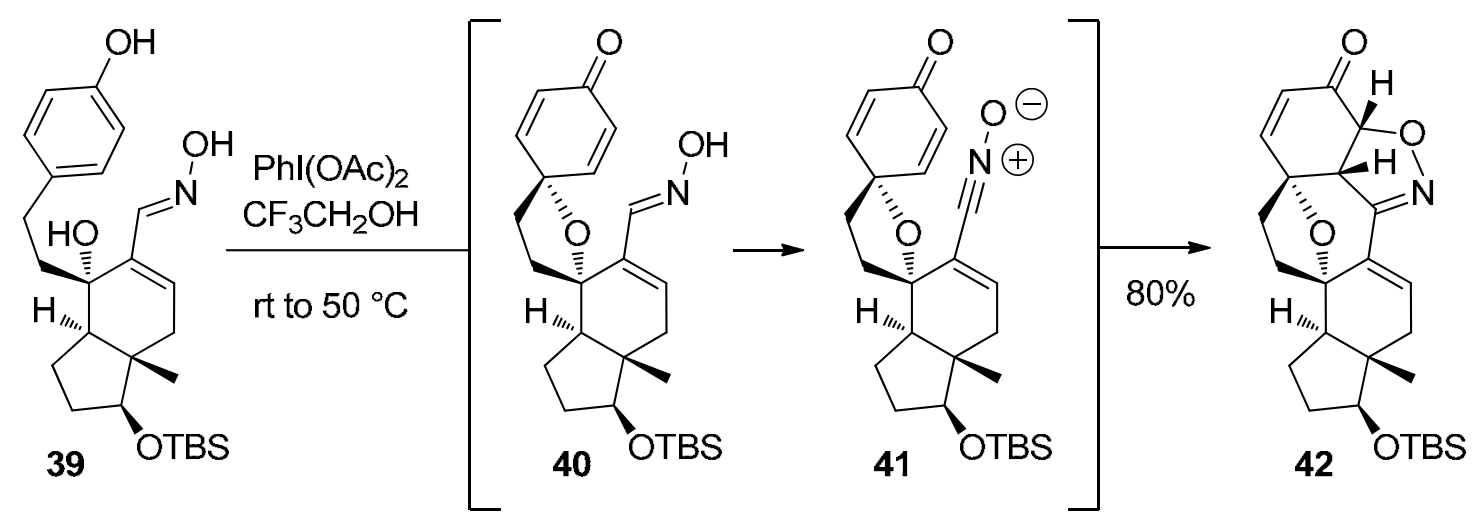

Scheme 12. Approach to cortistatin via tandem phenolic alkoxylation / INOC reaction.

In those cases where no oxidative phenolic amidation / alkoxylation steps are required prior to nitrile oxide generation, $\mathrm{MeOH}$ becomes a solvent of choice for DIB-mediated oxime oxidation. Pertinent examples appear in Scheme 13. ${ }^{19}$ As in the previous cases, a catalytic amount of TFA is essential for maximum efficiency. An instructive example of what might happen in the absence of protonic catalysis emerges from the work of Wang, $\mathrm{Hu}$, and collaborators, who found that the treatment of oxime $\mathbf{5 0}$ with DIB in methanol / catalytic TFA failed to produce the desired $\mathbf{5 1}$ (Scheme 14; decomposition of 50). ${ }^{22}$ It is likely that the basic amine neutralized the TFA, thereby denying protonic catalysis to the process and opening the door to side reactions.
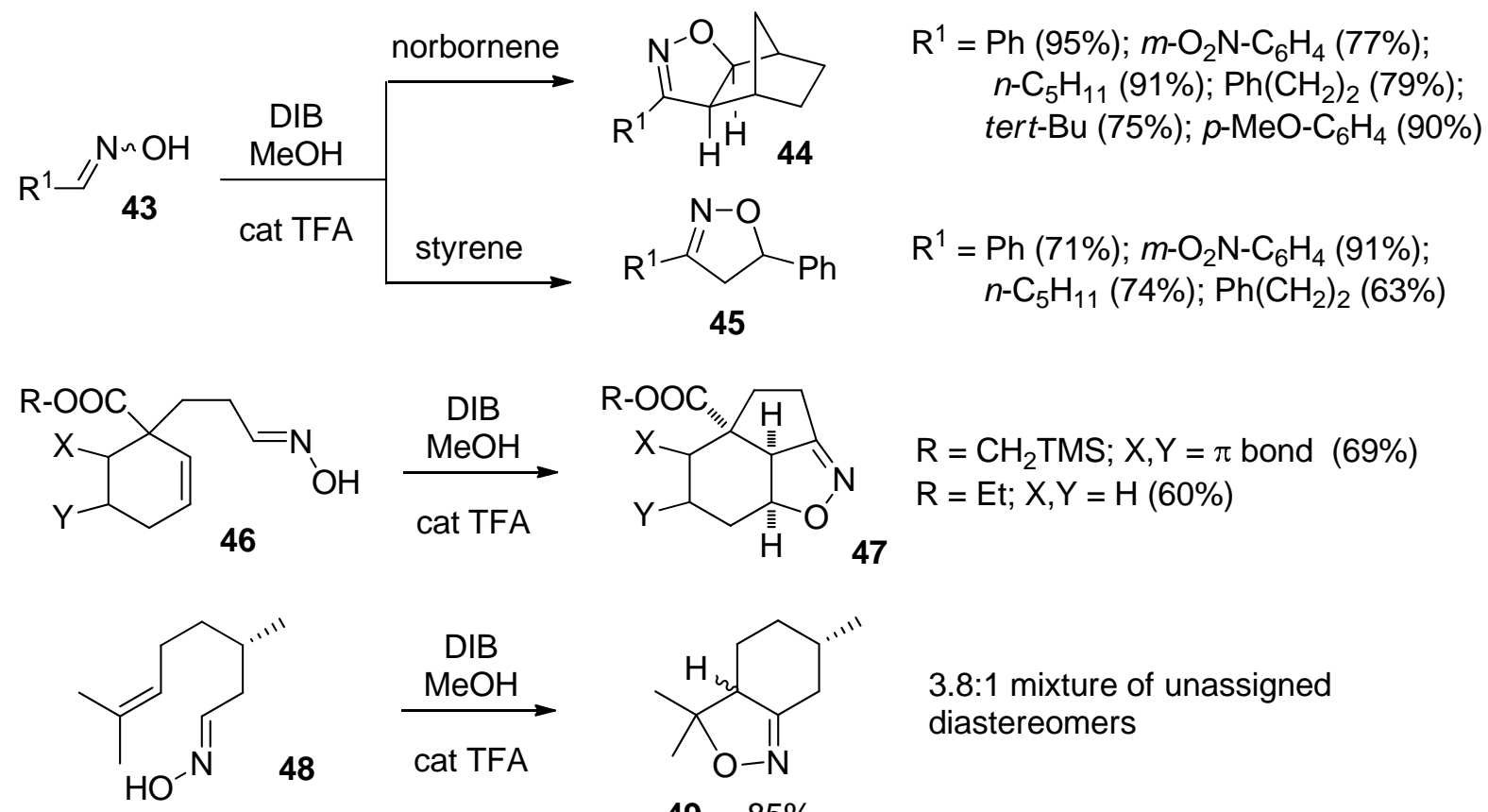

3.8:1 mixture of unassigned diastereomers

Scheme 13. Oxidation of aldoximes to nitrile oxides with methanolic DIB. 
<smiles>C=C[C@H]1CCCCN1CC/C=N/O</smiles>

50

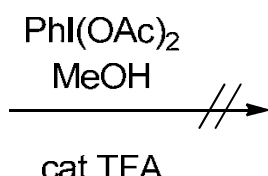

cat TFA<smiles>C1CCN2CCC3=NOC[C@@H]3[C@H]2C1</smiles>

51

Scheme 14. Failure of oxime 50 to undergo DIB-mediated conversion into 51.

A limitation of the above methodology is that the formation of isoxazoles from terminal alkynes is inefficient. For instance, the reaction of benzaldoxime with DIB in $\mathrm{MeOH} / \mathrm{TFA}$ and in the presence of phenylacetylene furnished $\mathbf{5 3}$ in only 50\% yield, while an analogous reaction with 1hexyne provided 54 in a modest $16 \%$ yield (Scheme 15). In either case, much benzonitrile oxide dimer (3,4-diphenyl-1,2,5-oxadiazole-2-oxide) was formed, indicating that the poor yields were due to a side reaction that was subtracting the alkyne from the medium. All indications implicated a competing formation of reactive alkynyliodonium species, ${ }^{23}$ which might then combine with various nucleophiles present in the medium, including $\mathrm{MeOH}$, to form a host of different products. Interestingly, shortly after the appearance of our own work Hou described a method for the synthesis of $\alpha$-acyloxy ketones (Scheme 16) by the reaction of terminal alkynes with DIB. A plausible mechanism indeed involves alkynyliodonium intermediates $5 \mathbf{5 6}^{24}$

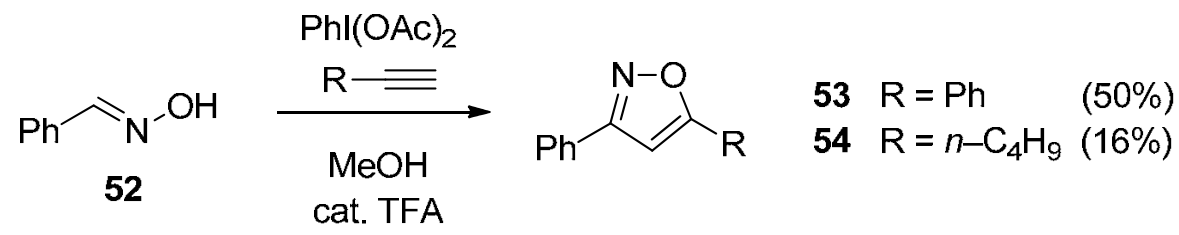

Scheme 15. Unsatisfactory isoxazole formation from terminal alkynes.

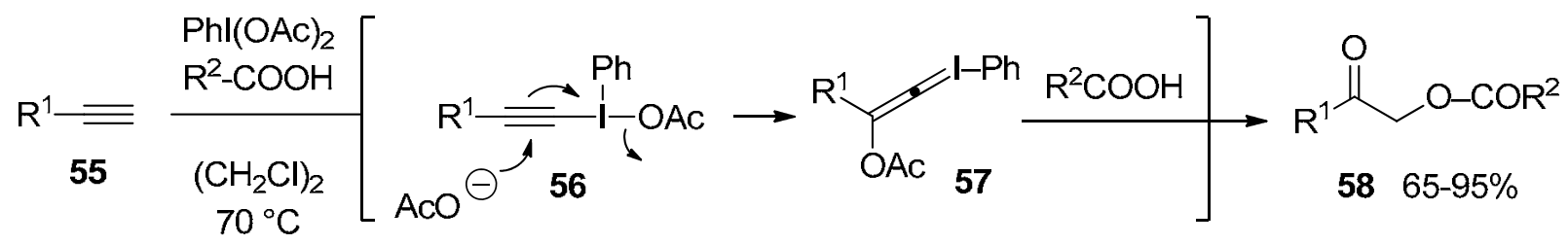

Scheme 16. DIB-mediated conversion of terminal alkynes into $\alpha$-acyloxyketones.

One may conclude from the foregoing that an internal alkyne should participate more efficiently in such DIB-mediated reactions; a surmise that finds confirmation in recent work by Boons and collaborators. ${ }^{25}$ Strained cycloalkynes such as $\mathbf{6 0}$ are especially effective trapping agents for nitrile oxides so generated (Scheme 17). 


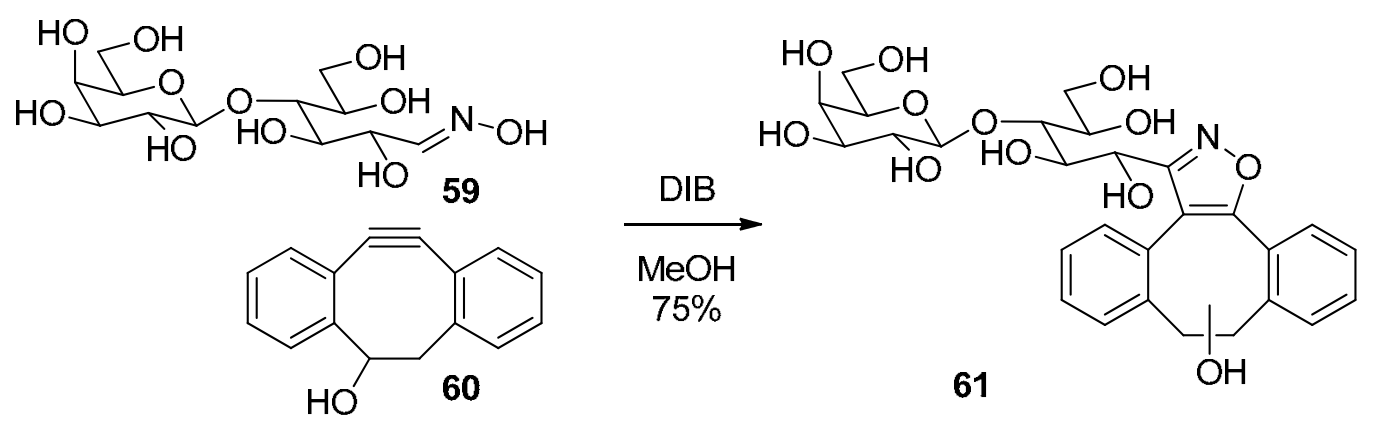

Scheme 17. Internal alkynes as traps for nitrile oxides obtained by DIB oxidation of oximes

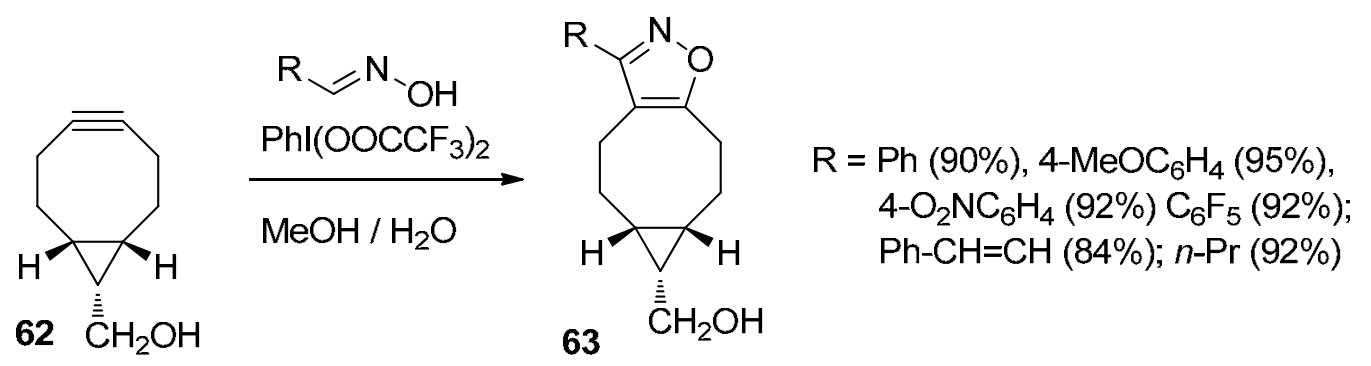

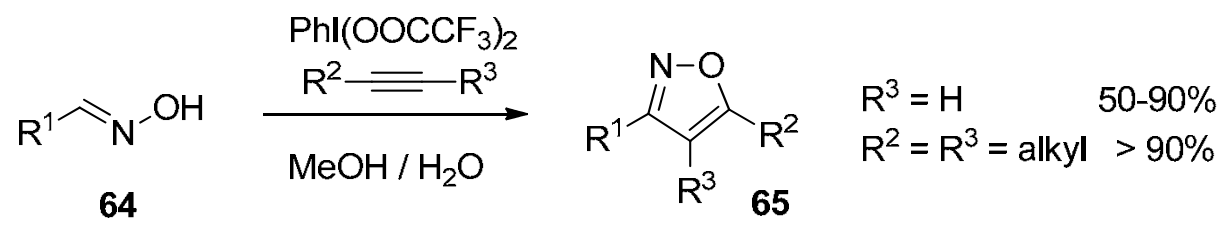

Scheme 18. Isooxazoles obtained by oxidation of oximes with PIFA in aqueous $\mathrm{MeOH}$. 


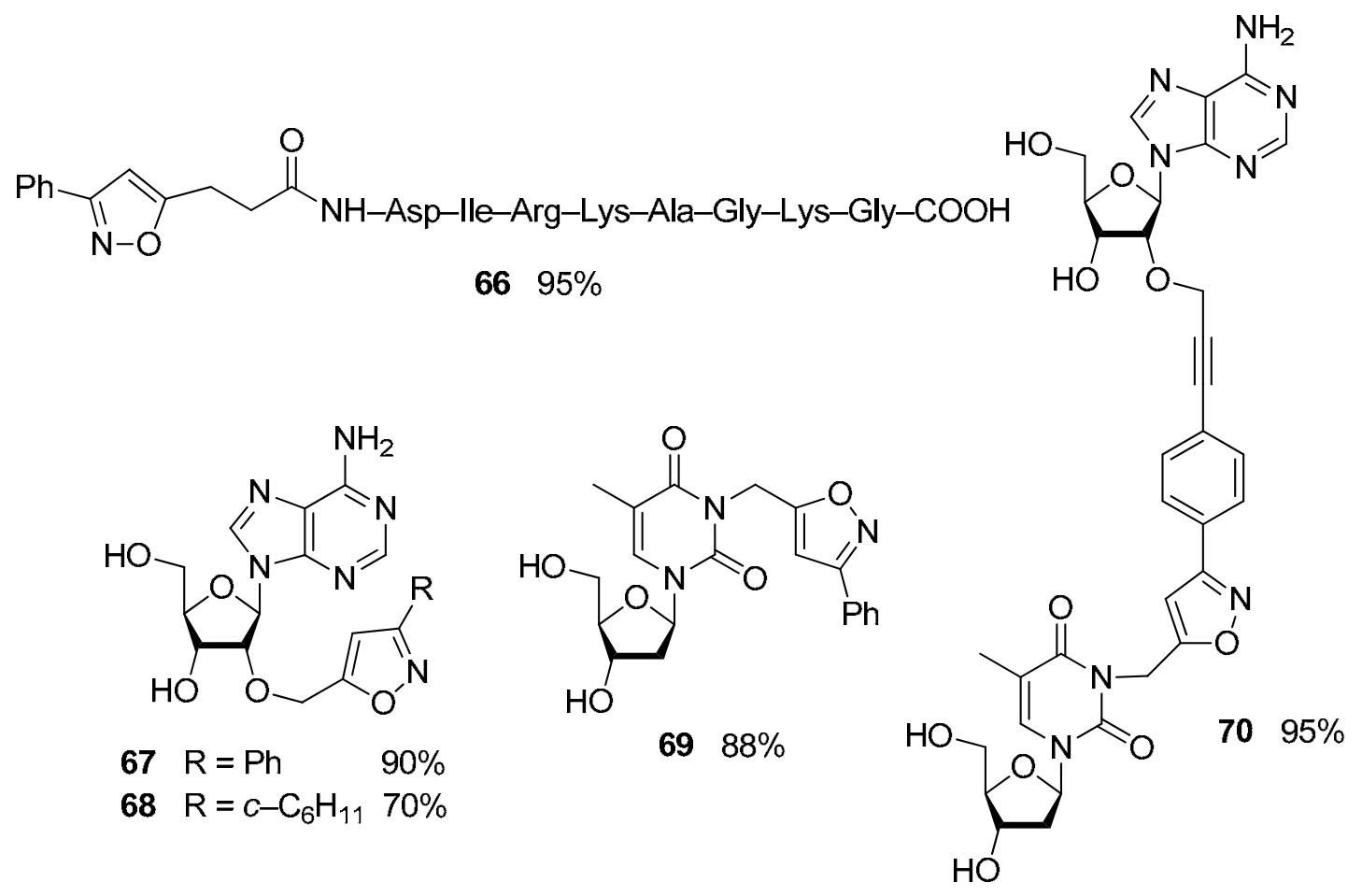

Scheme 19. Isoxazoles obtained from biomolecules incorporating terminal alkynes.

No TFA is required in this case. Van Delft and coworkers subsequently discovered that PIFA in aqueous $\mathrm{MeOH}$ is superior to DIB for this general reaction (Scheme 18). ${ }^{26}$ Even terminal alkynes provide isoxazoles efficiently under the new conditions. Evidently, the rate of oxime oxidation by PIFA is so fast that side reactions such as the one outlined in Scheme 16 no longer compete. Furthermore, the examples listed in Scheme 19 indicate that the methodology is exceptionally tolerant of spectator functionality: even substrates incorporating basic (lysine and arginine) or acidic (aspartic acid) aminoacids, nucleotides, and aminopurines (e.g., adenine) react efficiently. These reactions embody a new form of "click" technology, and under this rubric, a noteworthy application of the Boons methodology ${ }^{25}$ is the tunable click reactivity of azidooxime 71. Thus, reaction of the latter with $\mathbf{7 2}$ under thermal conditions leads to triazole 73, but oxidation of $\mathbf{7 1}$ with DIB in $\mathrm{MeOH}$ in the presence of $\mathbf{7 2}$ gives isoxazole $\mathbf{7 4}$ (Scheme 20). The reactions shown in Schemes 19-20 presage many significant applications in bio-organic chemistry. 


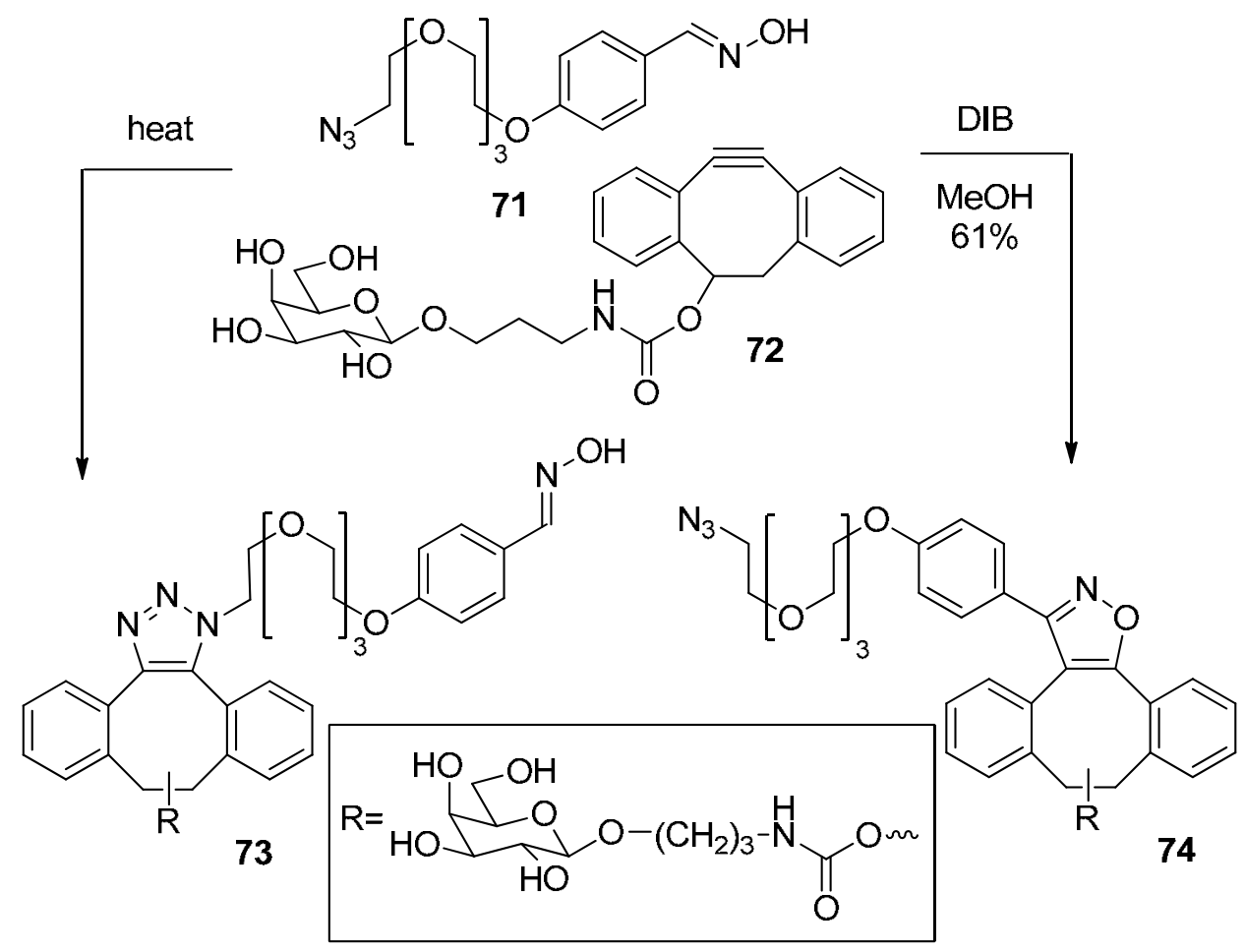

Scheme 20. Tunable click reactivity of oxime $\mathbf{7 1 .}$

The foregoing developments encouraged us to broaden the scope of the reaction of oximes with hypervalent iodine reagents. A synthetically appealing opportunity materialized in the form of an oxidation of 75, leading to carbethoxyformonitrile oxide (CEFNO): ${ }^{27}$ a useful (and safe) fulminic acid equivalent. ${ }^{28}$ Happily, methanolic DIB in the presence of TFA smoothly converted $\mathbf{7 5}$ into CEFNO, which was efficiently trapped in situ with norbornene and styrene (Scheme 21). ${ }^{29}$ Analogous reactions of oximinoacetone, $\mathbf{7 6}$ also proceeded in a satisfactory manner, albeit the yields of products 79-80 were lower than those obtained from 75. Regardless, the oxidation of oximes 7576 nicely complements other methods for the generation of $\alpha$-oxo-nitrile oxides. ${ }^{30}$

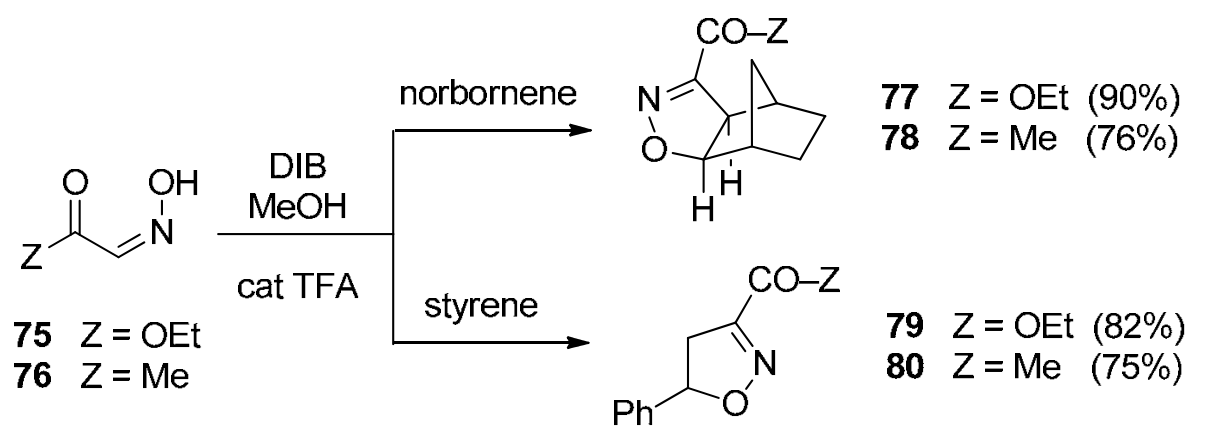

Scheme 21. Oxidation of $\alpha$-oxo-aldoximes with DIB in MeOH - TFA. 


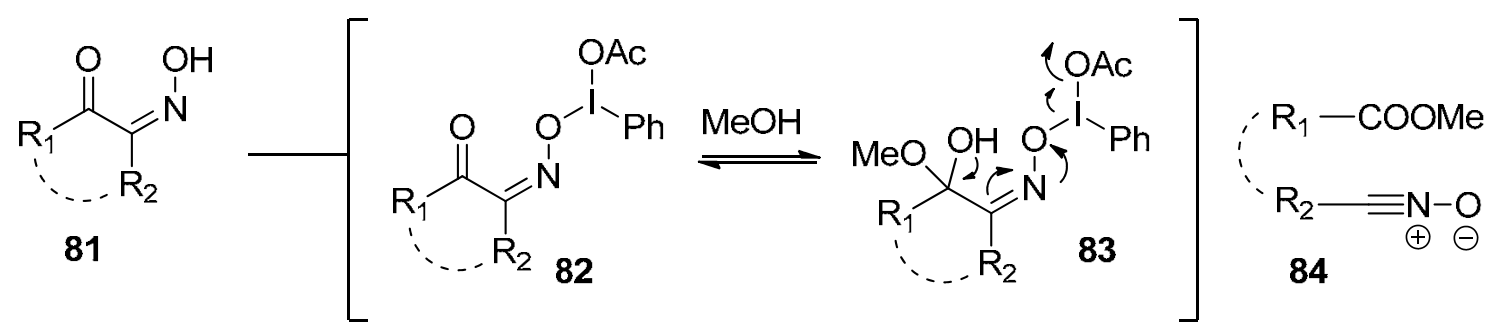

Scheme 22. Possible solvolytic nitrile oxide formation from $\alpha$-oxo-ketoximes.
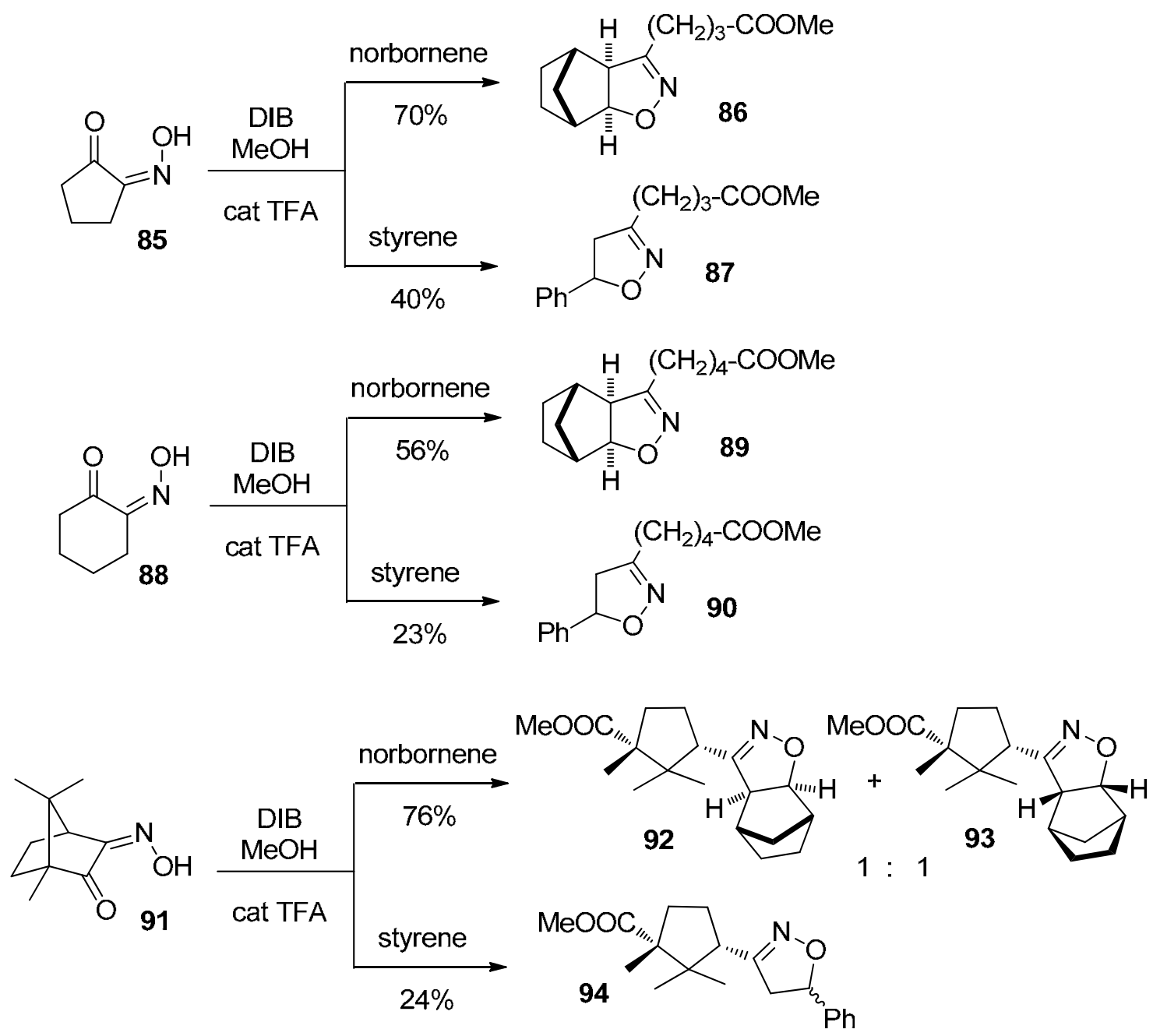

Scheme 23. Oxidation of $\alpha$-oxo-ketoximes with methanolic DIB.

Contrary to an aldoxime, an ordinary ketoxime cannot produce a nitrile oxide directly upon oxidation. However, a nitrile oxide could form as a result of the oxidation of an $\alpha$-oxo-ketoxime in a nucleophilic solvent such as $\mathrm{MeOH}$, through solvolytic fragmentation of the carbonyl-imino $\mathrm{C}-\mathrm{C}$ bond, perhaps through the mechanism depicted in Scheme 22. This is indeed the case. As seen in Scheme 23, the oxidation of representative $\alpha$-oxo-ketoxime $\mathbf{8 5}, \mathbf{8 8}$, and $\mathbf{9 1}$ with DIB in methanol 
proceeded in a satisfactory manner, although consistently higher yields of cycloadducts were obtained when norbonene, rather than styrene, was employed as a trap. The reasons for this remain unclear. It should be noted that norbornene adducts of the type $\mathbf{8 9}$ have been employed as building blocks for the synthesis of prostaglandin analogs. ${ }^{31}$ The methodology outlined in Scheme 23 offers a particularly direct avenue to these materials. Also worthy of note is the fact that the nitrile oxide arising from camphor-derived 91 reacted with norbornene to yield an essentially 1:1 mixture of diastereomeric adducts $\mathbf{8 9}$ and $\mathbf{9 0}$, which arise from the two possible exo-topologies of the cycloaddition step, while its styrene adduct $\mathbf{9 4}$ emerged as a 1:1 mixture of diastereomers. Evidently, cyloaddition reactions of this chiral nitrile oxide proceed with no stereoinduction whatsoever.

A limitation of this chemistry is that $\alpha, \alpha^{\prime}$-dioxoketoximes are generally poor substrates for solvolytic DIB oxidation (Scheme 24). To wit, oxime 95 yielded 78 as efficiently as did 76 (cf. Scheme 21), but 96 gave 77 in lower yield than 75, while the oxidations of 97 and 99 were no longer preparatively useful. As detailed elsewhere, ${ }^{29}$ inductive, resonance, and steric effects conspire to retard the rate of oxidation of $\alpha, \alpha^{\prime}$-dioxo substrates and of nucleophilic cleavage of the resulting reactive intermediates, hampering nitrile oxide formation and diminishing overall yields.
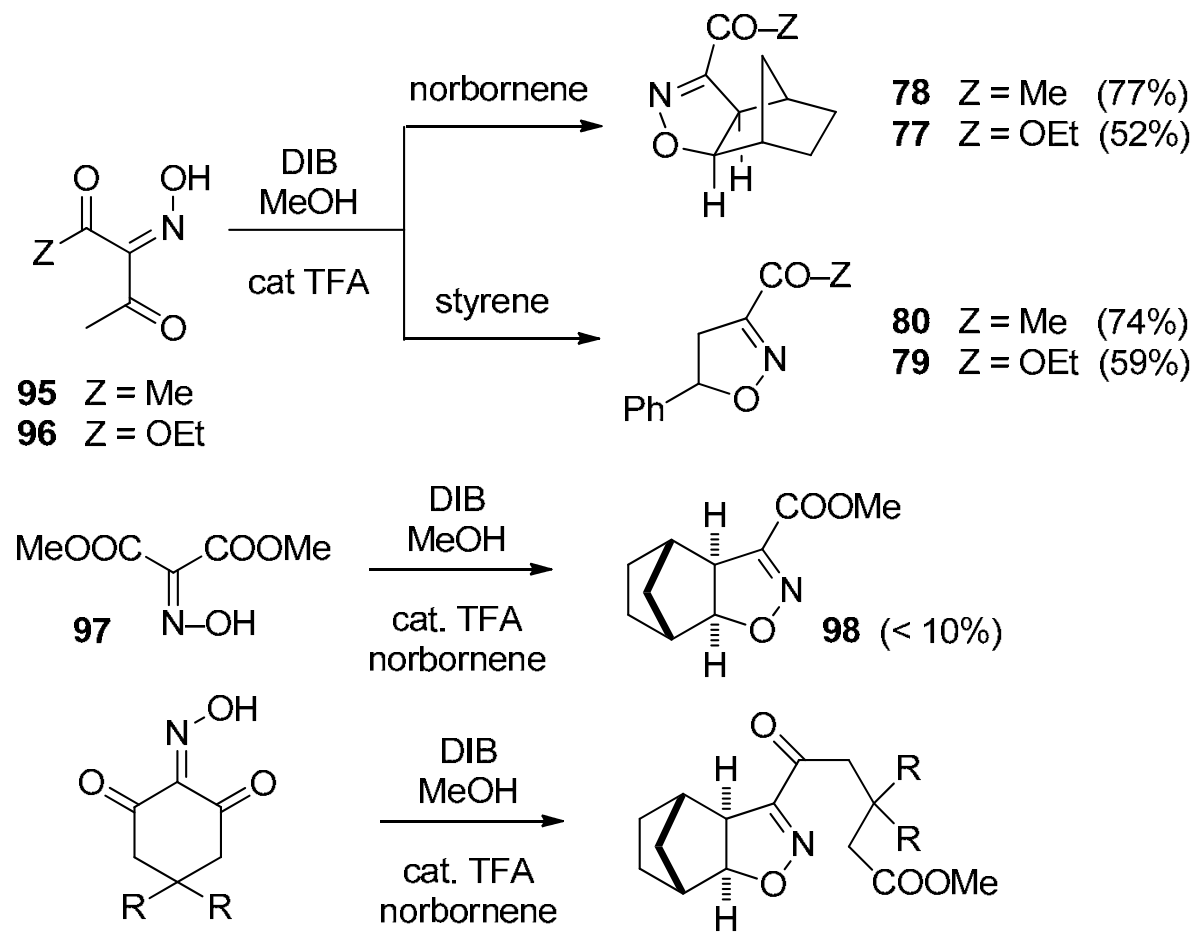

$99 \mathrm{R}=\mathrm{H}$ or $\mathrm{Me}$

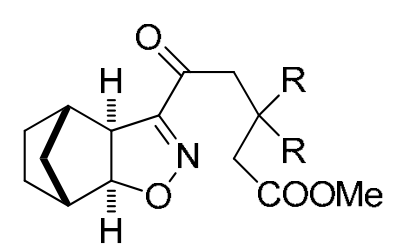

$100 \mathrm{R}=\mathrm{H}$ or $\mathrm{Me}(<10 \%)$

Scheme 24. Generally unsatisfactory oxidation of $\alpha, \alpha^{\prime}$-dioxo-ketoximes with methanolic DIB. 


\section{Conclusions}

The oxidation of oximes to nitrile oxides by the use of hypervalent iodine reagents provides new tactical opportunities for the synthesis of nitrogenous substances, natural or otherwise. While the first examples of this reaction ${ }^{13,14,17}$ predate our own contributions, the appearance of our 2009 paper ${ }^{19}$ seems to have rekindled interest in this noteworthy transformation. Indeed, numerous applications in natural product, bio-organic, heterocyclic, and materials chemistry have been described since. The method complements existing avenues to nitrile oxides, the usefulness of which in preparative operations is likely to make this chemistry of interest to a broad cross section of synthetic and medicinal chemists. In closing, we would be remiss not to underscore that the incentive to research the reactions discussed herein originated exclusively from a perceived need for new synthetic technology: Synthesis is, and will always be, the engine that drives chemical invention.

\section{Acknowledgements}

We thank the NSERC, CIHR, CFI, BCKDF, the Canada Research Chair Program (M.A.C.) and the University of British Columbia for support of our research program.

\section{References and Notes}

1. Monograph. (a) Varvoglis, A. Hypervalent Iodine in Organic Synthesis; Academic Press: San Diego, 1997. Reviews: (b) Varvoglis, A. Synthesis 1984, 709. (b) Stang, P. J.; Zhdankin, V. V. Chem. Rev. 1996, 96, 1123. (c) Wirth, T.; Hirt, U. H. Synthesis 1999, 1271. (d) Moriarty, R. M. Org. React. 2001, 57, 327. (e) Zhdankin V. V.; Stang, P. J. Chem. Rev. 2002, 102, 2523. (f) Kita, Y. Yakugaku Zasshi 2002, 122, 1011. (g) Hamamoto, H.; Anilkumar, G.; Tohma, H.; Kita, Y. Chem. Eur. J. 2002, 8, 5377. (h) Moriarty, R. M. J. Org. Chem. 2005, 70, 2893. (i) Wirth, T. Angew. Chem. Int. Ed. 2005, 44, 3656. (j) Zhdankin, V. V. J. Org. Chem. 2011, 76, 1186.

2. Reviews: (a) Ciufolini, M. A.; Braun, N. A.; Canesi, S.; Ousmer, M; Chang, J; Chai, D. Synthesis 2007, 3759. (b) Ciufolini, M. A.; Canesi, S.; Ousmer, M.; Braun, N. A. Tetrahedron 2006, 62, 5318. (c) Liang, H.; Ciufolini, M. A. Tetrahedron 2010, 66, 5884.

3. Reviews: (a) Pouységu, L.; Deffieux, D.; Quideau, S. Tetrahedron 2010, 66, 2235. (b) Roche, S. P.; Porco, J. A. Angew. Chem. Int. Ed. 2011, 50, 4068.

4. Hypervalent iodine reagents are also known to promote a limited number of oxidative phenolic amination reactions. (a) Scheffler, G.; Seike, H.; Sorensen, E. J. Angew. Chem. Int. Ed. 2000, 39, 4593. (b) Seike, H.; Sorensen, E. J. Synlett 2008, 695. (c) Mizutani, H.; Takayama, J.; Soeda, Y.; Honda, T. Tetrahedron Lett. 2002, 43, 2411. (d) Mizutani, H.; Takayama, J.; Soeda, Y.; Honda, T. Heterocycles 2004, 62, 343. (e) Mizutani, H.; Takayama, J.; Honda, T. Synlett 2005, 328.

5. (a) Braun, N. A.; Ciufolini, M. A.; Peters, K.; Peters, E.-M. Tetrahedron Lett. 1998, 39, 4667.

(b) Braun, N. A.; Ousmer, M.; Bray, J. D.; Bouchu, D.; Peters, K.; Peters, E.-M.; Ciufolini, M. 
A. J. Org. Chem. 2000, 65, 4397. This technology was developed in order to achieve biomimetic syntheses of FR-901483 and TAN-1251C: (c) Ousmer, M.; Braun, N. A.; Ciufolini, M. A. Org. Lett. 2001, 3, 765. (d) Ousmer, M.; Braun, N. A.; Bavoux, C.; Perrin, M.; Ciufolini, M. A. J. Am. Chem. Soc. 2001, 123, 7534. (e) Liang, H.; Ciufolini, M. A. In: Biomimetic Organic Synthesis, Vol 1; Poupon, E.; Nay, B., Eds.; Wiley-VCH: Weinheim, Germany 2011, Ch. 2.

6. This methodology was developed in connection with the synthesis of cylindricine and related substances: (a) Canesi, S.; Belmont, P.; Bouchu, D.; Rousset, L.; Ciufolini, M. A. Tetrahedron Lett. 2002, 43, 5193. (b) Canesi, S.; Bouchu, D.; Ciufolini, M. A. Angew. Chem., Int. Ed. 2004, 43, 4336; Angew. Chem. 2004, 116, 4436. (c) Liang, H.; Ciufolini, M. A. Chem. Eur. J. 2010, $16,13262$.

7. (a) Canesi, S; Bouchu, D.; Ciufolini, M. A. Org. Lett. 2005, 7, 175. (b) Liang, H.; Ciufolini, M. A. J. Org. Chem. 2008, 73, 4299.

8. Reviews on nitrile oxide cycloaddition reactions and synthetic applications thereof. (a) Grundmann, C. Synthesis 1970, 344. (b) Kozikowski, A. P. Acc. Chem. Res. 1984, 17, 410. (c) Padwa, A. In 1,3-Dipolar Cycloaddition Chemistry; John Wiley \& Sons: New York, 1984; Vols 1, 2. (d) Torssell, K. B. G. Nitrile Oxides, Nitrones, and Nitronates in Organic Synthesis; VCH Publishers: New York. 1988. (e) Gothelf, K. V.; Jørgensen, K. A. Chem. Rev. 1998, 98, 863. (f) Kanemasa, S.; Tsuge, O. Heterocycles 1990, 30, 719. (g) Stanley, L. M.; Sibi, M. P. Chem. Rev. 2008, 108, 2887. (h) Belen'kii, L. I. In Nitrile Oxides, Nitrones, and Nitronates in Organic Synthesis: Novel Strategies in Synthesis - 2nd Ed.; Feuer, H.; Ed.: John Wiley \& Sons: New Jersey 2008, pp 1-128.

9. By way of rationale, it is well established that an equatorial group at a position adjacent to the $\mathrm{N}$ atom in an $\mathrm{N}$-acylpiperidine (or a similarly constituted six-membered ring; e.g. an $\mathrm{N}$ acylmorpholine) experiences severe A1,3-like compression against the carbonyl or the R' groups of the amide.[ ref. 5b and literature cited therein] In the interest of minimizing such an interaction (worth several $\mathrm{kcal} / \mathrm{mol}$ ), compound $\mathbf{1 0}$ cyclizes through a transition state in which the nascent $N$-acylmorpholine ring assumes a conformation in which the smaller $\mathrm{H}$ atom is left experiencing such an interaction, while the bulkier benzyl group occupies a more favorable axial orientation.

10. Liang, H.; Ciufolini, M. A. Org. Lett. 2010, 12, 1760.

11. Mendelsohn, B. A.; Ciufolini, M. A. Org. Lett. 2009, 11, 4736.

12. Reviews on INOC chemistry. (a) Mulzer, J. In Organic Synthesis Highlights; Mulzer, J., Altenbach, H. J., Braun, M., Krohn, K., Reissig, H. U., Eds.; VCH: Weinheim 1990; Vol. I, p 77. (b) Nair, V.; Suja, T. D. Tetrahedron 2007, 63, 12247. See especially pp 12255-12259.

13. Radhakrishna, A. S.; Sivaprakash, K.; Singh, B. B. Synth. Commun. 1991, 21, 1625.

14. (a) Tanaka, S.; Ito, M.; Kishikawa, K.; Kohmoto, S.; Yamamoto, M. Nippon Kagaku Kaishi 2002, 3, 471. (b) Chatterjee, N.; Pandit, P.; Halder, S.; Patra, A.; Maiti, D. K. J. Org. Chem. 2008, 73, 7775.

15. Raihan, M. J.; Kavala, V.; Kuo, C.-W.; Rama Raju, B.; Yao, C. F. Green. Chem. 2010, 12, 1090. 
16. (a) Das, B.; Holla, H.; Mahender, G.; Banerjee, J.; Ravinder Reddy, M. Tetrahedron Lett. 2004, 45, 7347. (b) Das, B.; Holla, H.; Maheder, G.; Venkateswarlu, K. Bangdar, B. P. Synthesis 2005 , 1572.

17. Yang, H. T.; Ruan, X. J.; Miao, C. B.; Sun, X. Q. Tetrahedron Lett. 2010, 51, 6056.

18. For instance, hypervalent iodine reagents can promote oxidative deoximation of oximes. (a) De, S. K.; Mallik, A. K. Tetrahedron Lett. 1998, 39, 2389. (b) Bose, D. S.; Srinivas, P. Synlett 1998, 977. (c) Chaudhari, S. S.; Akamanchi, K. G. Tetrahedron Lett. 1998, 39, 3209. (d) Chaudhari, S. S.; Akamanchi, K. G. Synthesis 1999, 760. (e) Corsaro, A.; Chiacchio, U.; Librando, V.; Pistara, V.; Rescifina, A. Synthesis 2000, 1469. (f) Bose, D. S.; Narsaiah, A. V. Synth. Commun. 1999, 29, 937. Such an event would bar nitrile oxide formation, and we had no notion of whether the rate of the tandem process would be competitive with that of deoximation.

19. Mendelsohn, B.; Lee, S.; Kim, S.; Teyssier, F.; Aulakh, V. S.; Ciufolini, M. A. Org. Lett. 2009 , $11,1539$.

20. Ghosh, H.; Patel, B. K. Org. Biomol. Chem. 2010, 8, 384.

21. Frie, J. L.; Jeffrey, C. S.; Sorensen, E. J. Org. Lett. 2009, 11, 5394.

22. Su, D. Y.; Wang, X. Y.; Shao, C. W.; Xu, J.; Zhu, R.; Hu, Y. J. Org. Chem. 2011, 76, 188.

23. (a) Rebrovic, L.; Koser, G. F. J. Org. Chem. 1984, 49, 4700. (b) Margida, A. J.; Koser, G. F. J. Org. Chem. 1984, 49, 4703. (c) Lodaya, J. S.; Koser, G. F. J. Org. Chem. 1990, 55, 1513. See also refs. $1 \mathrm{~b}$ and $1 \mathrm{e}$.

24. Mo, D. L.; Dai, L. X.; Hou, X. L. Tetrahedron Lett. 2009, 50, 5578.

25. Sanders, B. C.; Friscourt, F.; Ledin, P. A.; Mbua, N. E.; Arumugam, S.; Guo, J.; Boltje, T. J.; Popik, V. V.; Boons, G.-J. J. Am. Chem. Soc. 2011, 133, 949.

26. Jawalekar, A. M.; Reubsaet, E.; Rutjes, F. P. J. T.; van Delft, F. Chem. Commun. 2011, 47, 3198.

27. Leading references. (a) Skinner, G. S. J. Am. Chem. Soc. 1924, 46, 731. (b) Panizzi, L. Gazz. Chim. Ital. 1939, 69, 332. (c) Vaughan, W. R.; Spencer, J. L. J. Org. Chem. 1960, 25, 1160.

28. Kozikowski, A. P.; Adamczyk, M. J. Org. Chem. 1983, 48, 366.

29. Jen, T.; Mendelsohn, B.; Ciufolini, M. A. J. Org. Chem. 2011, 76, 728.

30. E.g.: (a) Cecchi, L.; De Sarlo, F.; Machetti, F. Eur. J. Org. Chem. 2006, 4852. (b) Machetti, F.; Cecchi, L.; Trogu, E.; De Sarlo, F. Eur. J. Org. Chem. 2007, 4352. (c) Trogu, E.; De Sarlo, F.; Machetti, F. Chem. Eur. J. 2009, 15, 7940. (d) Trogu, E.; Cecchi, L.; De Sarlo, F.; Guideri, L.; Ponticelli, F.; Machetti, F. Eur. J. Org. Chem. 2009, 5971.

31. Bondar, N. F.; Isaenya, L. P.; Skupskaya, R. V.; Lakhvich, F. A. Russ. J. Org. Chem. 2003, 39, 1089. 


\section{Authors Biographies}

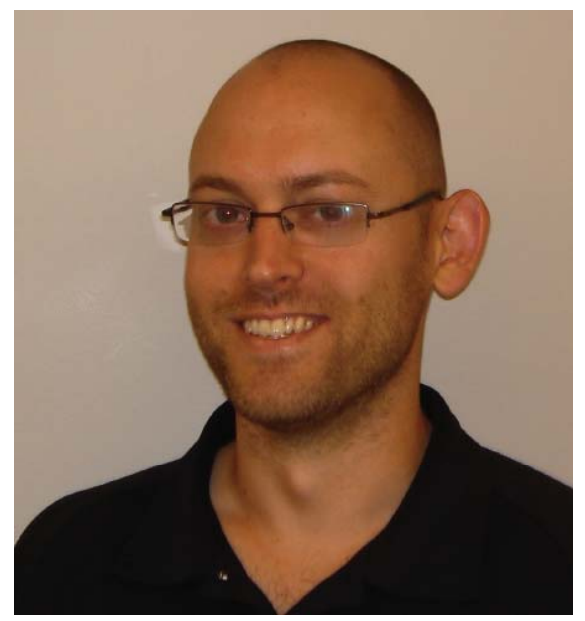

Charles Dylan Turner: was born in Vacaville, California, USA. In 2005 he graduated summa cum laude from California Polytechnic State University, San Luis Obispo, with BS degree in Chemistry. In 2006 he joined the research group of Professor Marco A. Ciufolini at the University of British Columbia in Vancouver, Canada. His current research centers on the total synthesis of the anticancer natural products quinocarcin and telomestatin.

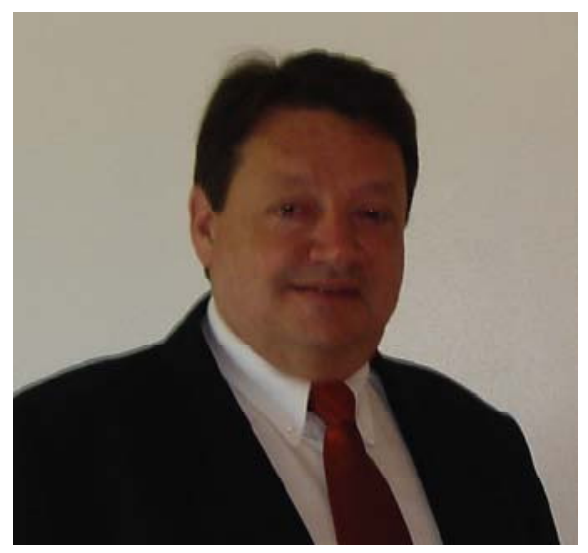

Marco A. Ciufolini: is a native of Rome, Italy. He received a B.S. (1978) from Spring Hill College, Mobile, AL, and a Ph.D. (1981) from the University of Michigan, under the direction of Prof. M. Koreeda. After postdoctoral studies in the group of Prof. S. Danishefsky, at Yale University, he started his independent career (1984) at Rice University, where he rose to the rank of Professor of Chemistry. At the end of 1997, he left Rice to accept a Chair of organic chemistry at the Ecole Supérieure de Chimie, Physique et Electronique de Lyon and the University of Lyon, France, but in mid-2004 he returned to North America as the holder of the Canada Research Chair in Synthetic Organic Chemistry at the University of British Columbia, Vancouver, BC. His research interests are in organic and medicinal chemistry, with focus on the development of new methods for the preparation of nitrogenous substances and on the application of these techniques to the synthesis of heterocyclic natural products. 